\title{
Mathematics Curriculum Development
}

\author{
Koeno Gravemeijer and Anita Rampal
}

\section{Introduction}

The purpose of TSG 32 was to gather congress participants who are interested in research, policy or design that focuses on mathematics curriculum development. The TSG aimed at including presentations and discussions of the state-of-the-art in this topic area and new trends and developments in research and practice in mathematics education. Curriculum was perceived at two levels. On a national or state level, where the focus is on content and goals for the primary or secondary school mathematics curriculum. And on a more specific level of curriculum design which concerns the developmental trajectories of mathematics content and the best ways to represent them. In relation to this theme, we especially solicited papers that might foster the deliberation on the varied aims of the curriculum and bring concerns and experiences from different contexts.

The papers that were submitted could be arranged in four categories, which were used to structure the sessions:

- Authenticity and Inquiry

- Implementation

Organizers Co-chairs: Anita Rampal (India), Koeno Gravemeijer (the Netherlands); Team Members: HyeJeong Hwang (Korea), Margaret Brown (United Kingdom), Cyril Julie (South Africa); Liaison IPC Member: Cheryl Praeger (Australia).

K. Gravemeijer ( $\square)$

Eindhoven School of Education, Eindhoven, The Netherlands

e-mail: koeno@gravemeijer.nl

A. Rampal

Department of Education, University of Delhi, Delhi, India

e-mail: anita.rampal@gmail.com

(C) The Author(s) 2015

S.J. Cho (ed.), The Proceedings of the 12th International Congress

on Mathematical Education, DOI 10.1007/978-3-319-12688-3_57 
- The Syllabus

- Math Topics

Each session consisted of one long paper and a number of short paper presentations.

\section{Authenticity and Inquiry}

The session on authenticity and inquiry started with a presentation by Anita Rampal (India) (with Katie Makar (Australia)) of a paper on the topic of embedding authenticity and cultural relevance in primary mathematics. She observed that there is an increasing need for a more democratic and universal participation in elementary school, better numeracy among citizens and mathematical competence and expertise in the workforce, but that accountability systems have often worked in opposition to these elements to further suppress authentic problems in favor of those that can be easily tested. In their paper they highlighted approaches to tackle this problem using innovative curriculum materials in two diverse contexts-India and Australia. These materials were designed with the specific intent of increasing students' opportunities for learning mathematics in ways that are relevant to their familiar and local contexts and cultures. Specifically, to increase the use of culturally relevant thematic units in Indian primary school textbooks, and to embed inquiry-based learning using authentic problems in the Australian curriculum. As half of India's children do not complete elementary education owing to the alienation they face in school, a social constructivist approach has been adopted to ensure more inclusive and democratic participation of all children. This has led to the development of new textbooks which, especially at the primary level, attempt to locate mathematics in the diverse socio-cultural contexts of children's lives. A new national curriculum in Australia has sought to align the curricula across the states and territories and to reflect a stronger focus on disciplinary knowledge and proficiencies, general capabilities and cross-curricular priorities. A seven year longitudinal study has been researching teachers' experiences and pedagogical practices as they adopt and adapt inquiry-based teaching in their classrooms, by engaging students in addressing ill-structured problems that required students to continually re-negotiate their understandings of mathematics within a rich context.

This presentation was followed by three short paper presentations:

Shelley Dole (with Katie Makar, and Gillies Robyn) (Australia) presented a paper on how the inquiry pedagogy of the intended curriculum was enacted in Australian classrooms. To answer this question, they assembled video data, classroom observations, and interviews with teachers involved in a design research-project. This concerned 40 teachers (of Grades Prep to 7) who attended three professional development meetings per year, and taught 3-4 inquiry-mathematics units per year. The teacher meetings provided the teachers with an opportunity to discuss their thoughts about and experiences with inquiry. It showed that during these meetings 
teachers identified the benefits of inquiry. The classroom observations showed that the teachers were keen to undertake inquiry in their classrooms, but it showed also that inquiry is difficult for both teachers and students.

Danrong Ying (China) presented a study in which a comparison was made between inquiry tasks in three high school mathematics series in China. Two textbooks were based on the "Obligatory High School Standards", issued by the Chinese Ministry of Education, the other one was based on the "Shanghai Primary and Middle School Mathematics Curriculum Standards". The results reveal that mathematics inquiry tasks in three series mainly focused on "Number and Algebra". And even though the textbooks based on the "Obligatory High School Standards", gave various names to mathematical inquiry tasks, the actual presentation was mainly in the form of pure mathematical problems. In all three selected textbook series, the tasks labeled "experiment" all focused on using information technology to solve mathematical problems, while clear procedures were given.

Yamei Zhu (with Yun Gan, and Yaping Yang) (China) presented a paper on a comparative study of mathematics textbooks in Shanghai, Singapore and America. Some differences could be traced to the different cultural backgrounds. The Shanghai and the Singapore textbooks reflected a typical "eastern culture" and the American textbooks a typical "western culture". In the former the teacher is dominant, the textbooks offer structured and coherent knowledge, and there is an emphasis on pure mathematics which leads to "the multi-steps, logic-based and knowledge-rich mathematics problems". The American textbooks focus on what the authors qualify as "isolated and incoherent knowledge". At the same time, the USA textbooks use context problems which convey the meaning of mathematics study.

\section{Implementation}

The session on implementation started off with a presentation by Margaret Brown (with Jeremy Hodgen, and Dietmar Kuchemann) (United Kingdom) of a paper on changing the grade 7 curriculum in algebra and multiplicative thinking at classroom level in response to assessment data. In this presentation, the methods and results of the project were reported. Phase 1 of the project took the form of assessment of attitude and understanding in the areas of algebra and multiplicative thinking of a nationally representative sample of students in Grades 6-8 in England. The results revealed that the majority of students in Grade 8 had an understanding of ratio, which did not extend beyond scaling up by multiplication by a small whole number, while $40 \%$ had an understanding of algebra, which did not extend beyond that of treating letters as objects or direct evaluation. Phase 2 of the project involved working with eight teacher researchers to research the understandings of their own Grade 7 students in these areas and to explore ways of improving their students' understanding. The understanding of many students was 'patchy'. To some extent this reflected a lack of connections in the understanding of the teacher researchers. This in turn 
limited the possibility of formative assessment. Analysis of the recommended schemes of work and of the most popular textbooks showed that each new topic was covered rapidly and superficially, with teachers often reducing the content to routine procedures to enable students to do the class work exercises. There was no time for deep treatment of topics, discussing the power of different models/representations, relating them to connected ideas, or discussing how they could be applied to more complex problems. In Phase 3 the project is extended to more teachers using interlinked sequences of 40 outline lessons designed by the research team.

This presentation was followed by two short paper presentations and a chat with presenters.

Ji-Won Son (United States) presented a short report on a comparative study on inquiry tasks in three senior high school mathematics textbook series in China. The purpose of the paper was to examine teachers' transformation of cognitive demand of textbook problems. A survey was carried out among 183 teachers teaching from 1st to 6th Grades, of whom eight teachers were observed. It showed that the cognitive demand of the textbook problems plays an important role in deciding the cognitive demand of the problems used by the teachers, but the teachers used lower level teacher questions. An in depth and broad analysis with respect to teachers' textbook use showed that a wide variety of factors influenced the quality of instruction.

LV Shi-hu (with YE Bei-bei and CAO Chun-yan) (China) presented a study on the implementation of the new mathematics curriculum for compulsory education in Chinese mainland. Surveys were carried out in the Gansu province, among 300 primary and middle school teachers, and 1,360 students in Grades 7-9. The surveys used both questionnaires and interviews. A comparison with earlier surveys showed that the application of the Standards had increased, and that the teachers had acquired a better understanding of the Standards, even though only $20 \%$ said to "completely understand" the Standards. The student questionnaires revealed that different teaching methods, especially cooperative learning, exploratory learning and independent learning were used by the teachers.

\section{The Syllabus}

In the third session the syllabus was the central theme. Tamsin Meaney (Sweden) (with Colleen McMurchy and Tony Trinick, New Zealand) presented a paper on the contested space of Maori mathematics curriculum development in Aotearoa-New Zealand. This concerned the development of the first mathematics curriculum in te reo Māori, the Māori language, in New Zealand in the 1990s and its revision in the mid-2000s. They argued that the development of national mathematics curricula in te reo Māori involved contestation, not just around indigenous knowledge and epistemology, but also around language. The authors stressed the power relationships that existed between the various actors involved in the curriculum development process. They argued that the power embedded in the Ministry of Education 
allowed it to keep a firm grip on the curriculum development process, although the process was contested and in some cases subverted by Māori because of their expectations about the use of te reo Māori. There has been a strong movement amongst some Māori communities for language revitalization and growth since the 1970s. The revision of curricula was thus done with an expectation that it would be less proscriptive, supporting a more community-developed approach to the mathematics that would actually be taught in schools. This supported Māori parents' aspirations for greater fluency in their children's Māori language and opportunities to strengthen their children's tribal identities. More of the specialist mathematical terms and grammatical structures were developed so that mathematics could be taught more easily at higher levels in Maori. The 2008 curriculum minimized the linguistic confusion that arose from the introduction of many new Māori terms in the 1990s. The revised curriculum has an emphasis on mathematical communication that has clearly been indicated by the inclusion of a Māori language strand. So this process like the earlier one has contributed to the teaching of mathematics in te reo Māori.

This presentation was followed by a series of short paper presentations, and a chat with presenters.

Anette Jahnke (Sweden) presented a paper on the process of developing a syllabus, in which she presented critical reflections from a syllabus developer. She had been involved in writing the new (2011) Swedish national syllabuses for kindergarten, elementary and upper secondary school. She observed that every tenth year politicians initiate a reform, often only in one part of the school system. Usually a small number of teachers and/or teacher educators are hired to write a draft during a very short period of time, which is then sent out a number of times for reactions. Often reforms did not result in coherent syllabus from $\mathrm{K}-12$. One of the reasons of failure of syllabus reform was that teachers did not understand or even mis-understood the syllabus. This resulted in very restrictive instructions to the syllabus writers.

Tomas Hojgaard (Denmark) presented a paper on what he called "The fighting of syllabusitis". He coined the term syllabusitis as a name for a disease consisting of focusing on the mastering of individual subjects. As an alternative he suggested using a set of mathematical competencies, while using a matrix structure of the relation between subject specific competencies and subject matter. He argued that such a matrix structure has proven to be a crucial element when attempting to put the competence idea into educational practice, not least because it makes it possible for teachers to take an active part in such a project and welcome it as a developmental tool.

\section{Math Topics}

In the last session we gave attention to specific math topics. Tomoko Yanagimoto (with Yuichi Hayano) (Japan) presented a paper on the teaching and learning of knot theory in school mathematics. Knot theory is studied actively world-wide, 
since, even though the basis is simple, it has many unsolved problems. Furthermore, it can be related to scientific research fields, such as Genome DNA. The members of the project have written up teaching contents for pupils from elementary school to high school as a book, "Teaching and Learning of Knot Theory in School Mathematics". Experimental teaching - based on the results of the study on teaching knot theory in elementary school and junior high school-started in public junior high school in 2009 and in elementary school in 2011. It showed that knot theory was effective in helping students improve their spatial visualization, in elementary school pupils in particular. In junior and senior high schools, knot theory led students to become more engaged in their mathematical activities. Typical for this project was that mathematicians, researchers of mathematics education and professional practitioners of education cooperated, respecting and trying to understand researches of others' professional fields while creating materials for education. An expert in knot theory could indicate the value of each teaching material from the view point of knot theory. Researchers of mathematics education could indicate the value of each teaching material from the view point of mathematics education. School teachers could realize the teaching in their classrooms based on their pupils' cognition. Officials of mathematics education society could help the teachers carry out the experimental teaching in their public school by asking the director of the school.

This presentation was followed by short paper presentations.

Qintong $\mathrm{Hu}$ (with $\mathrm{J}$-Won Son) (United States) presented a comparative study of the initial treatment of the concept of function in selected math textbooks in the US and China. They analyzed the initial treatment of the concept of function in three curricula: a US traditional text, a US Standards-based text, and a Chinese reform text. The textbook problems were analyzed on three dimensions, contextual feature, response type, and cognitive expectation. It showed that both the US traditional textbook and the Chinese textbook were designed for teacher-centered instruction. While the reform-oriented US textbook was designed for student-centered instruction. However, the US reform-oriented textbook was more similar to the Chinese textbook in putting problems in illustrative contexts, emphasizing connections, reasoning and proof.

Linda Arnold (with Ji-Won Son) (United States) presented a paper on a content and problem analysis on learning opportunities related to linear relationships in USA textbooks. The textbook analysis methods included both problem and content analysis. They examined examples of four types of mathematics textbooks: (1) two different commercial texts; (2) a so-called "back-to-basics" text; (2) a reform-oriented U. S. National Science Foundation (NSF) funded text; and (4) a once commonly-used historic text, published a generation ago. There were numerous similarities between the historic textbook and present day commercial texts, suggesting that little had changed over 50 years. All of the problems of the NSF-funded text involved real world context and were geared toward extended thinking, in contrast to the back-to-basics and historic texts that showed a high degree of procedural presentation. It further showed that students using commercial texts were expected to master an especially broad array of objectives. 
Sunyoung Han (Korea) presented a study on the effect of science, technology, engineering and mathematics (STEM) project based learning (PBL) on students' achievement. Even though Science, Technology, Engineering and Mathematics (STEM) are critical fields to ensure a financially sound national economy, students have been under-enrolling in STEM courses. To address this problem, STEM Project Based Learning (PBL) developed an instructional method using "ill-defined tasks". The purpose of the study was to examine how STEM PBL lessons affect students' achievement in terms of four mathematical topic areas (i.e. algebra, geometry, probability and problem solving). The participants were diverse students enrolled in a small, urban, and low socio-economic high school. The study showed STEM PBL positively influenced most mathematical topics.

The Topic Study Group meeting ended with some closing remarks by Anita Rampal and Koeno Gravemeijer. It was noted that the special time for chat with presenters' gave greater opportunity for small group intensive discussions that brought out specific issues from different cultural and country contexts.

\section{Endnote}

The design and organization of the four TSG sessions was carried out collaboratively by the organizing team. Unfortunately, Cyril Julie was eventually unable to attend the Congress and the TSG.

Open Access This chapter is distributed under the terms of the Creative Commons Attribution Noncommercial License, which permits any noncommercial use, distribution, and reproduction in any medium, provided the original author(s) and source are credited. 